\title{
Algunos hitos
}

\section{Some milestones}

\author{
Julio Yarmuch ${ }^{1}$
}

Nuestra Revista de Cirugía ha logrado perdurar en el tiempo, desde que comenzara su publicación en 1952. Tan importante como su antigüedad es la regularidad de la aparición de sus números, estos son publicados cada 2 meses y en los últimos 20 años no recuerdo que alguno se haya atrasado; son pocos los medios de divulgación científica en nuestro país que pueden ostentar estas características, las que son muy valoradas por las databases mundiales de este tipo de revistas.

A lo largo de los últimos años hemos ido desarrollando cada vez más nuestra publicación electrónica, sin abandonar hasta ahora la versión en papel. El acceso a nuestra página web se puede lograr fácilmente, siendo libre para todo usuario; desde allí se puede interactuar mediante diversos links con otros medios sociales. Permite la lectura de todo lo publicado en los últimos años y se está estudiando la posibilidad de digitalizar también hacia atrás los números de antes del año 2000. El proceso editorial al día de hoy permite que estén en la web los Resúmenes de los artículos ya aceptados y editados, los que en este momento incluyen hasta el número 4 del año 2020. Se está trabajando para habilitar la publicación íntegra adelantada de todo el material ya aceptado y editado.

Estamos en condiciones de incluir en las publicaciones links hacia videos que enriquezcan los artículos, por lo que los autores pueden comenzar a incluirlos. Por ahora, estos debieran tener alrededor de
5 minutos de duración y referirse preferentemente a maniobras o innovaciones de técnicas quirúrgicas.

La tendencia universal es hacia la publicación electrónica. Lenta, pero inexorablemente la mayoría de las revistas han ido implementando y perfeccionando este medio, lo que en el mediano plazo ha implicado disminuir la publicación en papel. La Revista de Cirugía ha disminuido su tiraje y, lo más probable es que en los próximos años tienda a persistir solo en su versión electrónica.

El DOI (Digital Object Identifier) es una forma de identificar un objeto digital (por ejemplo un artículo electrónico de una revista, un capítulo de un libro electrónico...) sin importar su URL, de forma que si ésta cambia, el objeto sigue teniendo la misma identificación. Este identificador era dado en un comienzo por Scielo o Elsevier. En la actualidad, desde hace unos meses, hemos obtenido que nuestra revista sea la propietaria de sus DOI, de modo que estos son asignados autónomamente por nosotros.

Uno de los problemas universales de los medios de divulgación científica es el plagio. Este es difícil de pesquisar y probar. En los próximos meses estaremos adscritos a un sistema mundial de descubrimiento de este robo intelectual, lo que aumentará nuestra presencia y credibilidad internacional y nacional.

Si bien hemos avanzado, aún resta mucho por hacer y perfeccionar. En eso estamos.
'Editor Revista de Cirugía previamente Revista Chilena de Cirugía).

Correspondencia a: Dr. Julio Yarmuch jyarmuched@gmail.com 